\title{
29 The Value System Designer - AN INFRASTRUCTURE FOR BUILDING THE VIRTUAL ENTERPRISE
}

\author{
Bernhard R. Katzy \\ University BW Munich, Germany
}

\begin{abstract}
Much research has been conducted on what a virtual organisation is and how it should work. With this paper I will address the question, how a virtual enterprise can be designed to be agile and to so best support its short-term business opportunities. I shall present $a$ framework for the organisational design and the changing business roles of the 'business architect' who constructs the various phases of the virtual enterprise's lifecycle. I refer to this infrastructure for creating virtual enterprises as the 'Value System Designer'; a set of methods and tools to select partners, reengineer business- and logistic processes and to set up an information and communication platform for the virtual enterprise. These methods and tools have been developed in the EU project TELEflow and the Eureka 'Virtuelle Fabik' project. I shall focus on the experiences gained from the numerous projects and summarise crucial success factors for designing virtual enterprises. Thus, this paper gives insights and applicable know-how for companies and managing engineers acting as virtual enterprise architects, for example leaders of project consortia or joint ventures or as first-tier suppliers co-ordinating supplier (sub-) nets.
\end{abstract}

\section{THE NEED FOR AND STRUCTURE OF VIRTUAL ORGANIZATIONS}

The term 'Virtual Organisations' has become a buzzword of lately and is used in a multitude of contexts, all promising business success. However, the virtue of virtuality is clearly confined to adapted applications in specific business environments. I will therefore set out to clarify my stance on the contingencies of virtual organisations, which will allow managers to anticipate success and failure within their own context.

\footnotetext{
- CeTIM- Center for Technology and Innovation Management, University BW Munich, Werner-von-Heisenberg-Weg 39, 85577 Neubiberg, Germany, tel.: +4989 60043255 , fax: + 4989 6004 3260, e-mail: bernhard.katzy@unibw-muenchen.de
} 


\section{Virtual organisations are a solution for turbulent business environments}

It is generally acknowledged that firms today face a dynamic environment, changing at an increasingly rapid pace. Market opportunities in particular can arise and disappear again within a short period of time. However, the ability of traditional organisations to adapt to these changes remains limited. We refer to this predicament, where the environment changes more rapidly than organisations can adapt to, as a turbulent environment.

Virtual organisations are designed to behave in an agile manner towards market opportunities. This is achieved by stimulating organisational flexibility, particularly the competence to concurrently design a customer's product or service and the processes to produce or deliver it. This flexibility is supported by (but should not be confused with) the structure of a virtual organisation.

Three basic elements, the customer value, the value system and the network describe the virtual organisation for our purposes (Figure 1) and allow us to formulate answers for the following questions:

1. Why was the value system created? The value system is designed to create value of a business opportunity. The value is the force that drives continuous restructuring of the value system.

2. How can the value be created? Value is created with the value system as business processes are adapted to the requirements of the short-term business opportunity.

3. Who are the potential partners? The potentially participating partners of the network will in most cases be related parties; independent companies, but also decentralised profit centres or strategic business units of a global holding.

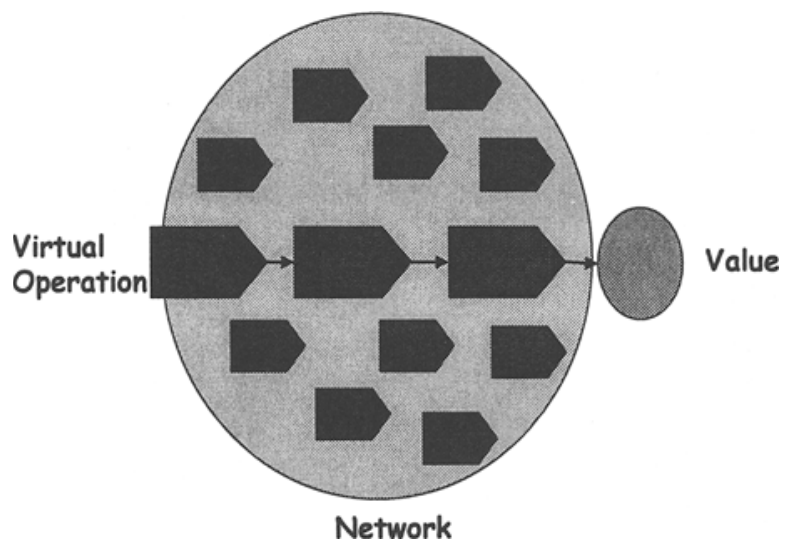

Figure 1 - The structure of virtual organisations [Katzy, Schuh, 1997]

\section{The Value System is a business driven virtual organisation}

Competition in the information age will no longer take place among single companies, but among clusters of companies that work together to exploit the value of a business opportunity. The structure of virtual organisations is a useful model to describe this configuration. We call such virtual organisations Value Systems (VS); organised actions and interactions bringing processes together from different companies, different sites, suppliers, OEMs, distributors, service providers, etc. that 
co-operate to provide the customer service [N.N., 1997]. Popular examples of this form of co-operation are Nike and Diesel.

With the emerging information society, co-operation on a global scale can be expected to become more intense and will increase strategic relevance because distance will no longer be a limiting issue [N.N., 1995]. This transformation might turn into a competitive advantage for large multinationals that are already have a global organisational structure. European companies, however, are smaller in size compared to their US and Asian counterparts. To reap the benefits of the information society, it is therefore often necessary for the European firms to engage in co-operative strategies to so create global presence.

Lacking the power of the large multinationals, smaller companies will have to seize the opportunity to substantially improve their competitiveness by creating, leading and sharing win-win constellations with their partners. This in turn requires advanced management competence, or will at least call for managers broadening their interest domain. They shall have to leave their turf and actively re-engineer inter-company processes within the Virtual System (Figure 2).

The Essence of Virtual Manufacturing

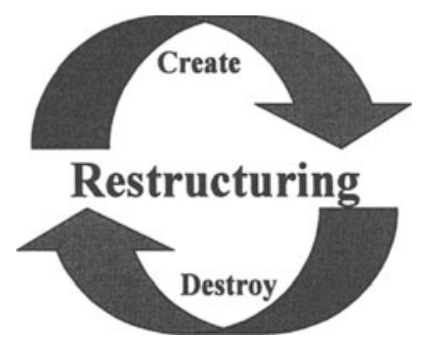

Agility or Nimbleness, is the capability to thrive on unpredictable change

Figure 2 - Dynamic Restructuring is the essence of virtual enterprises

In other words, value systems excel in dynamically changing global markets, because ever-new business opportunities can be identified and addressed using a new design of the VS. The value system redesign approach supports the competence to engineer and re-engineer VS in a systematic and professional way. Real cases (see below) show that this competence of concurrent engineering is a source of sustainable competitive advantage.

Agility describes activity and behaviour, not a structure. Of course behaviour is backed by the organisational structure, supported or in the traditional organisation in most cases - hindered. In the next section we refer to the 'Value System Designer' as the infrastructure for the manager, engineer or team who activates the virtual organisation. 


\section{THE VALUE SYSTEM DESIGNER}

\section{A lifecycle based framework for designing virtual enterprises}

The Value System lifecycle provides a framework for all enterprise engineering activities to design a virtual enterprise (Figure 3 ). In its pre-phase the business concept is defined, which then is architectured into an architectural product and cooperation in the configuration phase. Value System processes are engineered during the design phase and consecutively operation follows. As all Value Systems are by definition temporary, de-briefing and wind-up of the co-operation requires special attention in the disbandment phase.

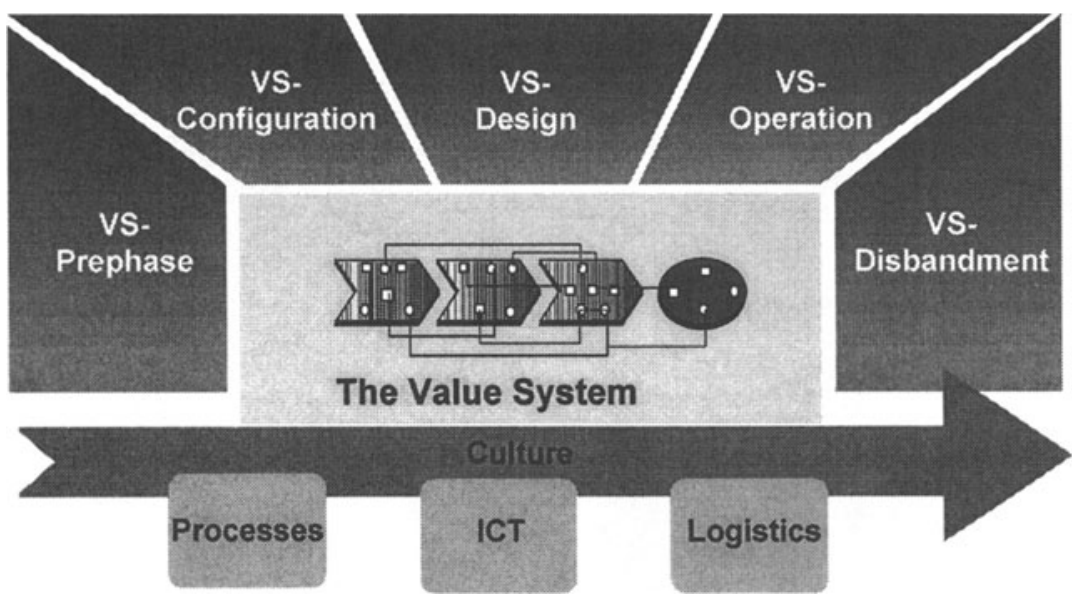

Figure 3 - The Life Cycle Approach of the Value System [N.N., 1998]

Tools to support the phases mentioned are already available. The following list is a mere illustration:

- Product specification methods for the pre-phase

- Competence database to identify the best partners for the Value System in the configuration phase

- Modelling tool for network processes and logistics in the design phase

- Performance measuring systems for the operations and disbandment phase.

Special IT implementation methods are available to rapidly engineer and implement 'disposable micro work-flows' in the operation phase.

In order to rapidly respond to a brief window of opportunity in the market, engineering and implementation competencies need to be pre-installed and on standby for use. The network of partners serves as the platform for these modules and can so be accessed and applied to each individual business case. The most critical success factor proves to be the co-operative culture within the network. Further modules were tested such as, business and work processes, an information and communication platform and a logistics platform [Katzy, Obozinski, 1998].

Concurrent engineering activities in the virtual organisation cannot be based on hierarchical chains of command and control. After years of co-operating in the network distinct roles and expertise of individual partners will emerge that are essential in a certain phase of the Value System's lifecycle. For the individual firm 
this will translate in a shift in strategic positioning. Was a strategy based on the product or service with the organisation supporting all phases of its lifecycle. Nowadays the virtual organisation strategies are increasingly defined around its competencies (e.g. the design of new products, the engineering of processes, management of operations, supply of technologies) that are dominant in one phase of the Value System lifecycle. The network will continually monitor the environment to seek new and/or different business opportunities for each competency.

\section{Roles and design tasks in the Virtual Enterprise}

Based on experience, six roles can be defined and serve as an aid to define genuine strategic positions for any partner in a virtual organisation (Figure 4). The roles can also be used to analyse the requirement specifications for the development of more specific methods and tools to design virtual enterprises. The broker's responsibility is to market the network and retail the competencies of potential virtual factories. This person should be an entrepreneurial person in the early phase of a Value System, procuring new projects for the network. Thus, the broker acts as a facilitator between customers and production.

The competence manager provides the engineering knowledge on the available technologies and competencies of the network and supports application engineering with the customers. During the configuration of the Value System this manager will concurrently engineer the Value System processes and select the best partners. The project manager supervises the operations of the Value System offering time project management and budget control and is process re-engineering, e.g. replacing partners who do not perform satisfactorily.

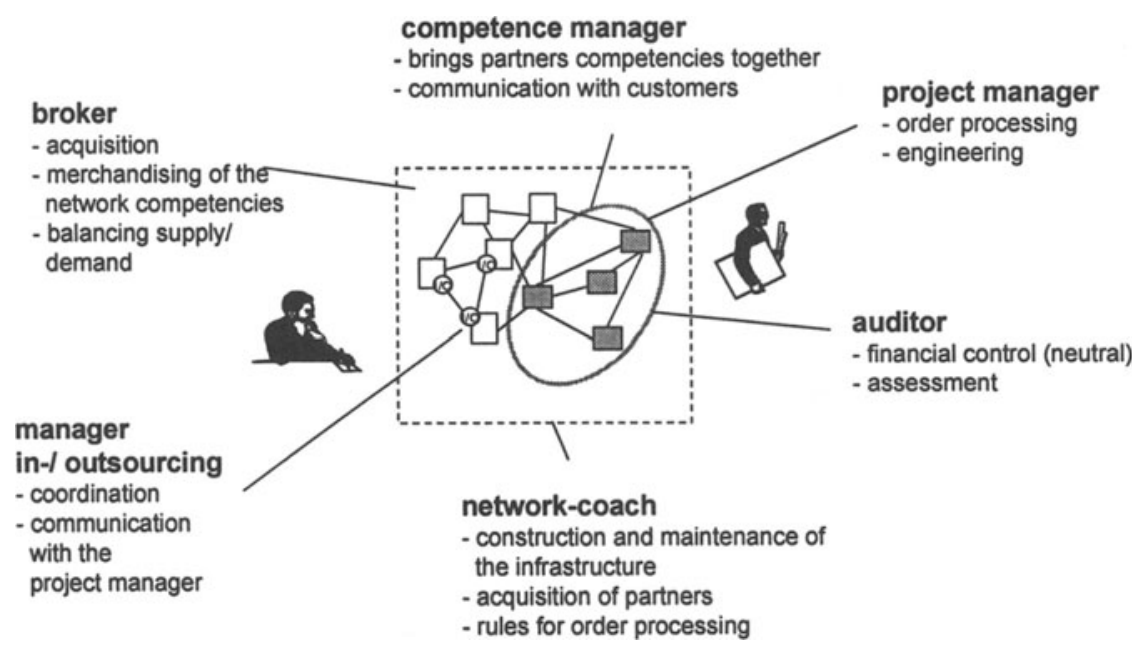

Figure 4 - Roles in the Virtual Factory [Katzy, Schuh, Millarg, 1996]

The in/outsourcing managers of each network partner develop a dedicated interface with the network and interact with Value Systems. They offer technological know how, resources and personal technological expertise to the network. While operating a Value System the in/outsourcing manager is responsible 
for a step in the value chain of the system and represents the interest of his firm. The auditor serves the network as a neutral financial auditor providing financial solidity due to his independent status. The latter becomes especially important in those cases where a track record for a customised on-demand engineered Value System is not available.

The network-coach is not related to a business opportunity but constantly serves as a coach of the network. This coaching is necessary to create the indispensable cooperative culture of the network and can be achieved by governance of the network, setting business rules and routines for co-operation, providing technological infrastructures in the network and managing relationships (and conflicts).

\section{VALUE SYSTEM DESIGNER COMPONENTS}

The Value System Designer is a direct of the TELEflow project;a telematics engineering project funded by the Telematics Applications Program ( $4^{\text {th }} \mathrm{EU}$ Framework Program 1994-98). Its objective was to integrate existing and develop new methods and tools for value system redesign. Four facets were developed for the 'Value System Designer' demonstrator. First the overall value system Designer methodology, second, the value system re-engineering tool NetMovals which combines an enhanced process modelling tool for inter-organisational application with the new business network modelling tool. Third, a logistics management solution repository (LMSR) providing a strategic controlling tool based on the balanced score card and detailed criteria to measure the performance of the virtual enterprise and fourth, the TELEflow Information Infrastructure, which provides services to quickly set-up project specific IT infrastructures. From these tools we now present the NetMovals and briefly indicate its integration with LMSR.

\section{NetMovals: modelling the networks of partners, resources and processes}

Business strategies are particularly successful, when existing industrial structures can be reconfigured to serve new business opportunities. Pre-existing resources and tested processes reduce the specific investment for capturing the new market opportunity. Networks of partners, of resources and of processes each need to be modelled. (Figure 5) Most important, however, are their interrelationships, which sum up strategic importance.

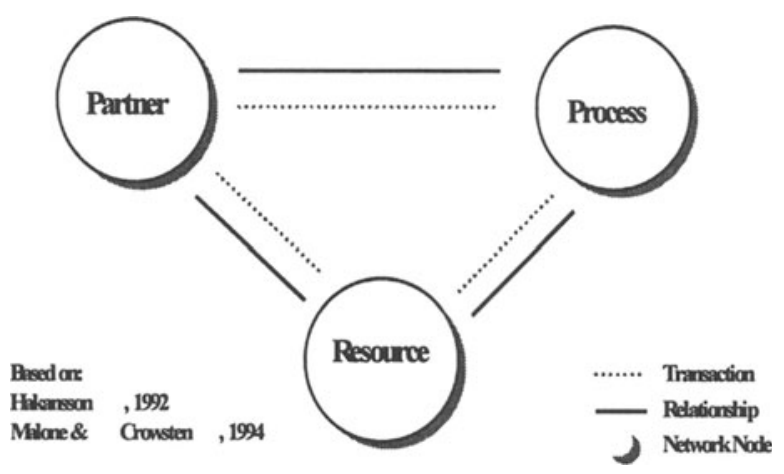

Figure 5: The Network Model 
Equally important is the effect of the sub-network interrelationships on time-to market. Setting-up resources and processes from scratch are a limiting factor for market penetration. The value system is a network of partners who provide the necessary competencies to supply a network of processes for the period needed to realise the value of a business opportunity regardless of their geographic distribution or ownership by partners. NetMovals further provides a process-modelling tool with a number of features, which are motivated by this field of application (Figure 6).

NetMovals combines the sub-network models as views to allow for the redesign of the value system with icon drag-and-drop facility. In this manner the different timeframes of the network evolution on one side, which may take years of trust building and on the other side rapid re-configuration of new business processes can be combined.

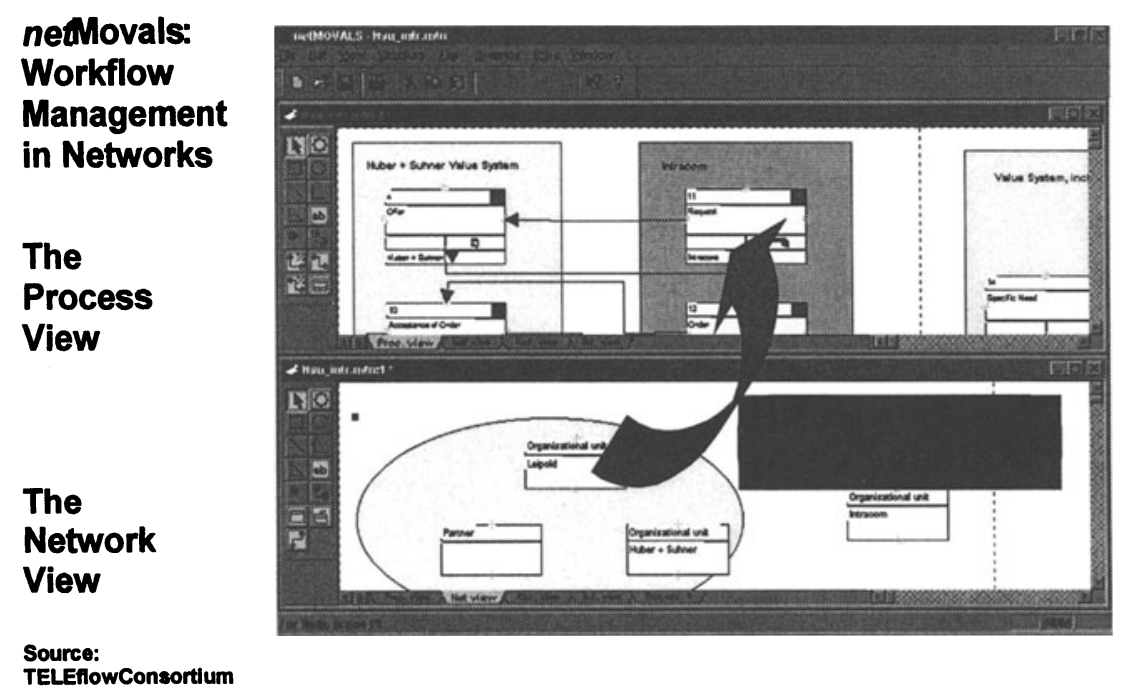

Figure 6 - Screen from the NetMovals Tool

Because the partners have been regarded as independent peers in the competitive scenario, the tool aims at supporting their negotiation as equals. Easy user interfaces and graphical functions as well as its multi-user capability are important features to support negotiation. Each user can for example control what information is publicly accessible in shared editing sessions as this information may affect the negotiation position. The amount of information given in the model has been limited, with the possibility to hyperlink extensions in order to meet the limited human information processing capacity during fast value system redesign decisions.

\section{Integration of Tools and Services}

Once the network and process models have been established, integration with other tools shall be provided, where necessary. The scenario of this integration draws on the fast configuration of Value System Designer services, which are needed for certain phases and tasks in the value system lifecycle. For such a scenario the ondemand integration of services and tools with simple browser technology and widespread business applications on the user side is the objective. NetMovals as an 
application, therefore, is delivered as a download and provides OLE interfaces for the integration with other off-the-shelf applications such as MS-Access or MSExcel. The logistics management repository LMSR on the other side requires expert consulting and will only exceptionally be installed at the user side. More often NetMovals models will be transferred to the logistics service provider to be handled by computer application and human experts. Redesign options from a logistics perspective, however, will then be returned as NetMovals models to the user.

\section{LESSONS LEARNED FROM BUSINESS PRACTICE CASES IN DESIGNING VIRTUAL ENTERPRISE}

The Value System Designer is the result of more than four years of industrial cooperative R\&D. Today, the 'Value System Designer' is a modular package of business solutions combining concepts, methods and tools to support the design of virtual organisations. Table 1 gives an overview of business practice cases, which have been undertaken to validate the 'Value System Designer' solutions.

\section{Lessons learned for the broker in virtual enterprises}

Three lessons learned concern the pro-active role of brokers that sum up to more agile behaviour of the virtual organisation.

1. The projects created value for their member firms through identifying market opportunities outside their core-business. These points to conditions of turbulent environments, where market opportunities emerge unpredictably and markets change an order of magnitude faster than the organisation can adapt. Clearly, this case of making business in non-related industries is not covered by traditional marketing analysis, where a firm's conduct and the requirements of for products are derived from the structure of the industry it is in [Bain, 1959]. Similarly, in turbulent environments the identification of dominant players, suppliers, customers, or competitors becomes difficult. As we have seen, firms change the roles they play to the extent that they simultaneously assume multiple roles in parallel Value Systems. Consequently, with increasing turbulence it becomes more difficult to identify the competitive forces [Porter, 1979] that these players create in the industry, rendering this framework a less valuable basis for marketing decisions.

2. Concurrent Engineering with the customer gained importance in the virtual organisation. Initially pure market access has been recognised as an important element of networks, where not all companies are equally situated in terms of access to profitable opportunities. In Prato, for example, many of the small textile-manufacturing firms are not in a position to access world wide customers. In this industrial district, merchants, "impannatores", provide access to market opportunities for the entire district [Kumar, Bielle, van Dissel, 1996]. The impannatore brings "an overview of external markets" and markets the services of other firms to "compete on the basis of price, innovation and service" (p. 207). In the construction industry, market access is provided by specialised project managers, who hire those crafts that are needed for a custom-designed building [Piore, Sabel, 1984]. In fact, the construction industry was discussed as a model for Value Systems. However, it turned out that virtual 
organisations imply a more active search for opportunities than simple market access. In construction, project managers organise the response to a customer request, but do not actively encourage or seek out new work. As it turned out, this was the motivation for a project launched by the Swiss construction industry to adapt the concept.

3. Market opportunities do not present themselves neatly labelled as such. Instead, it is necessary for broker to be able and willing to create opportunities and to stretch competencies beyond their primary business. Pümpin [1986] refers to the concept of value potential, which he defines as value that is embodied-but not yet exploited - in constellations of the environment. He makes the point that it is the active role of a promoter to develop and multiply a market opportunity through interaction with involved stakeholders. Unfortunately, not much is known about the process by which promoters develop new market opportunities. Innovation models, such as Abernathy and Utterbeck's concept of dominant design [1974], focus on describing the lifecycle of an industry, which has only limited value for the work of a broker.

In summary, identification of market opportunities provides member companies of virtual enterprises with access to applications to fit their competencies in businesses beyond their traditional industry boundaries. Membership in a network exposes the firms to ideas and demands they would otherwise not have seen. As a reservoir of market opportunities the network is specifically adapted to turbulent environments, where we have perceived market opportunities as short-term windows, emerging and disappearing again in an order of magnitude faster than the organisation can adapt to. Selecting from business opportunities requires more than simply picking off the shelf. Instead, to accommodate short-term market opportunities requires extensive concurrent engineering activities by the partner firms as well as on the level of the network.

\section{Lessons learned for the competence manager}

Three lessons learned concern the role of the competence manager as a core element of more agile behaviour of the virtual enterprise.

1. The conception of resources gradually evolved and expanded in the Value System. Initially, the view was quite limited: resources were machines. Descriptions of these machines across the industries was based on the generally accepted classification scheme and terminology from the DIN 8580 standard, which defines all possible machining operations. For example, cutting machines are described by how they cut metal (with a defined edge, by grinding, etc.); assembly machines by how they bind parts together (temporarily e.g. by screwing, permanently e.g. by welding, etc.). The manufacturing resources available in different companies were identified in this way and listed in the "technology capacity bourse" database. Similarly, in Prato, the function performed by each of the small textile companies is well defined based on the steps required for clothing production. Thus, dying, weaving, cutting or sewing a particular order can be allocated to a firm providing this function [Ritaine, 1990]. 


\begin{tabular}{|c|c|c|}
\hline $\begin{array}{l}\text { Manufacturing } \\
\text { Project }\end{array}$ & Description of Product & $\begin{array}{l}\text { Description of virtual enterprise design } \\
\text { process }\end{array}$ \\
\hline $\begin{array}{l}\text { Mechanism } \\
\text { to electrically } \\
\text { retract a car } \\
\text { steering } \\
\text { wheel }\end{array}$ & $\begin{array}{l}\text { The mechanism targets a market of less } \\
\text { than } 10.000 \text { items a year and is therefore } \\
\text { not interesting to auto suppliers used to lot } \\
\text { sizes of hundreds of thousands. } \\
\text { It is technically challenging, as it has to } \\
\text { meet safety standards of auto industry at } \\
\text { competitive manufacturing cost. }\end{array}$ & $\begin{array}{l}\text { The network was prepared to face such } \\
\text { opportunities, responding within two days } \\
\text { to the customer request } \\
\text { To engineer the process from the best } \\
\text { competencies, ten potential technologies } \\
\text { were identified. } \\
\text { In a co-operative effort with the customer } \\
\text { engineering changes of the product were } \\
\text { implemented and prototypes } \\
\text { manufactured. }\end{array}$ \\
\hline $\begin{array}{l}2 \text { Large } \\
\text { precision } \\
\text { base for tool } \\
\text { machine }\end{array}$ & $\begin{array}{l}\text { The base was a } 20-\mathrm{mm} \text { sheet metal, } \\
\text { roughly } 1 \mathrm{~m} \times 1.5-\mathrm{m} \text { in size. More than } \\
300 \text { holes were needed for the assembly of } \\
\text { all mechanisms of the tool machine. } \\
\text { Placement of the holes de-fined the tool } \\
\text { machine's precision. The piece was too } \\
\text { big for most machines. }\end{array}$ & $\begin{array}{l}\text { Alternative technologies such as drilling, } \\
\text { laser drilling, and water drilling were } \\
\text { identified and compared. } \\
\text { During process engineering a large } \\
\text { dimension tool machine was identified, on } \\
\text { which the piece could be machined in one } \\
\text { fixing. Value created was quality } \\
\text { improvement (because of one fixing), and } \\
75 \% \text { cost reduction. }\end{array}$ \\
\hline $\begin{array}{l}3 \text { Module for a } \\
\text { letter sorting } \\
\text { machine }\end{array}$ & $\begin{array}{l}\text { The manufacturing of a module of an } \\
\text { industrial postal letter sorting machines } \\
\text { that was fully engineered. To meet short } \\
\text { delivery deadlines, the manufacturer } \\
\text { needed additional manufacturing capacity. } \\
\text { The module was structured in mechanical } \\
\text { and electrical subassemblies, and painted } \\
\text { sheet metal as the cover and stand. }\end{array}$ & $\begin{array}{l}\text { Competencies from the network. E.g. } \\
\text { controller manufacturing for textile } \\
\text { machines, and sheet metal manufacturing } \\
\text { and painting from furniture industry were } \\
\text { brought together to engineer the specific } \\
\text { process for the customer project. }\end{array}$ \\
\hline $\begin{array}{l}4 \text { Air- } \\
\text { conditioning } \\
\text { unit }\end{array}$ & $\begin{array}{l}\text { The concept of an air-conditioning unit, } \\
\text { fitting a demand pocket in the upper range } \\
\text { of the market was engineered and } \\
\text { manufactured as a project lasting about } \\
\text { two years. }\end{array}$ & $\begin{array}{l}\text { During a presentation of the project } \\
\text { 'Virtuelle Fabrik' an engineer in the } \\
\text { audience revealed having a product } \\
\text { concept and asked the necessary } \\
\text { competencies to engineer the production } \\
\text { process from the network. On stage, } \\
\text { project members analyzed the idea and } \\
\text { proposed an initial architecture of } \\
\text { contributions form three partners. } \\
\text { Business was agreed, in a cooperative } \\
\text { effort with the customer the unit was } \\
\text { engineered, prototyped and } 50 \text { copies } \\
\text { manufactured after } 18 \text { month, further } \\
\text { orders are pending. }\end{array}$ \\
\hline $\begin{array}{l}5 \text { Re- } \\
\text { engineering } \\
\text { stability of a } \\
\text { large sun- } \\
\text { umbrella }\end{array}$ & $\begin{array}{l}\text { Finite element simulation competency of } \\
\text { an engineering firm in the network was } \\
\text { used to improve wind stability of large } \\
\text { restaurant umbrellas marketed by a textile } \\
\text { manufacturer. }\end{array}$ & $\begin{array}{l}\text { The network was prepared to face market } \\
\text { opportunities from outside its companies' } \\
\text { core-businesses. The network's brokers } \\
\text { channeled a customer request from textile } \\
\text { industry to highly specialized } \\
\text { competencies available in a firm from the } \\
\text { mechanical industry. }\end{array}$ \\
\hline
\end{tabular}

Table 1- Business practice case of designing virtual enterprises

2. Experiences of Value Systems revealed engineering services to be independent competencies that were not linked to machine tools but which were equally important for successful projects. These engineering capabilities were needed to back the network's competency to design and engineer complete customer 
solutions. Examples in the business practice cases included assembly competency, quality inspection and testing capabilities, project management or certification for ISO conformity. These capabilities required complex combinations of information technology (for CAD, CAE), testing devices, skilled engineers or accreditation. Chiesa and Barbeschi [1994] similarly point out that resources are not simple factors, but rather represent complex combinations of factors that give them a distinct and unique character.

3. As well as within the individual member companies, competencies were developed at the level of the network as a whole. Valuable competencies could include factors from multiple partner companies, enabling the network as a whole to respond to demands from the turbulent environment. From experiences from Value Systems, more stable sub-networks of partners emerged, which as a group proved to have competencies for applications, for example, in medical technology or precision machinery. Similar empirical evidence of developing competencies is reported from Norway, where a learning cycle was implemented in a regional learning network [Hanssen-Bauer, Snow, 1996]. Since these network competencies were even harder to describe, the 'competency manager' was needed as someone who knew what competencies were available across the various partner companies and which might be applied to a particular customer's problem.

\section{CONCLUSIONS}

I conclude by the concepts, methods and tools of the 'Value System Designer' three critical success factors for the design of virtual enterprises.

First, virtual enterprises prove to be most favourable when $80 \%$ customerspecified requests allow for $20 \%$ engineering improvements to make best use of the network's competencies. Fully specified products often created rigid constraints to the engineering of processes, whilst vague customer requirements give no guideline for an effective concurrent engineering process.

Second, virtual organisations require a fundamental change in the co-operative culture of most firms. Individual co-operation and teamwork are essential prerequisites for successful virtual enterprises. Even more difficult to change will be the decision and planning systems (e.g. MRP, ERP, Accounting, Strategic Planning) that are efficient for stable business but prevent fast reaction through local decision making in the virtual enterprise.

Third, the success of a virtual enterprise depends on a balanced provision of all value system designer roles in all phases. Virtual enterprises are constrained in their performance by the 'weakest link in the chain', the weakest role or phase in the Value System. Again, the advantage of virtual enterprises is to involve the best supplier for each service needed to deliver a customer specific solution.

In turbulent environments, where the configuration of Value Systems rapidly changes as the brief window of opportunity in the market opens and closes, virtual enterprises can be expected to outdo traditional firms. 


\section{CROSS-PROJECT CO-OPERATION IN THE ELECTRONIC DISCUSSION FORUM ON VIRTUAL ENTERPRISES}

More than 40 projects in the different areas of European RTD programmes address the issue of virtual enterprises, virtual organisations, virtual teams or closely related topics. Due to existing structures however, experts frequently ignore parallel work. At least, exchange of knowledge or combination of complementary results remains rare. The virtual enterprise forum (contact bernhard.katzy@unibw-muenchen.de) uses web-based technologies for clustering EU projects and to improve cross project knowledge creation and what are the critical success factors for implementing it. The Web-based discussion forum on virtual organisations (http://www.ve-forum.de) hosted by the NECTAR project (http://www.nectar.org) has become a series of physical workshops facilitated by the TELEflow project since 1997. This has created results that include the initiation of a cluster of 25 European active projects working on virtual organisations and a consolidated contribution to the elaboration of a key part in the work plan for the IST programme under the 5th F.P. The forum is open for participation.

\section{ACKNOWLEDGEMENT}

This work has been sponsored by the European Commission and the Swiss Bundesamt fur Bildung und Wissenschaft through the Telematics Engineering Project TELEflow and the Swiss Commission for Science and Technology through the EUREKA Project VIPP: I also wish to acknowledge our gratitude and appreciation to all the TELEflow and VIPP project partners for their contribution during the development of various ideas and concepts presented in this paper.

\section{REFERENCES}

1. Abernathy, W. J., Wayne, K.: The Limits of the Learning Curve, HBR, (3),1974, 109.

2. Bain, J.: Industrial Organization. New York, Wiley \& Sons, 1959.

3. Chiesa, V., Barbeschi, M.: Technology Strategy in Competence-based Competition, in: Hamel, G., Heene, A. (eds.), Competence Based Competition, London, Wiley \& Sons, 1994, 293-314.

4. Hanssen-Bauer, J., Snow, C. C.: Responding to Hypercompetition: The Structure and Processes of a Regional Learning Network Organization, OS, 7 (4),1996, 413-427.

5. Katzy, B. R., Obozinski, V.: Value System Redesign. In: Proceedings of the 9th International Conference on Database and Expert Systems Applications (DEXA'98), Vienna, IEEE, 1998, .

6. Katzy, B. R., Schuh, G.: The Virtual Enterprise, in: Molina, A., Sanchez, J. M., Kusiak, A. (eds.), Handbook of Life Cycle Engineering: Concepts, Methods and Tools, New York, Chapman \& Hall, 1997.

7. Katzy, B. R., Schuh, G., Millarg, K.: Die virtuelle Fabrik - Produzieren in Netzwerken, Technische Rundschau, (43), 1996, 30-34.

8. Kumar, K., van Dissel, H. G., Bielle, P.: The Merchant of Prato - Revisited: Towards a Third Rationality of Information Systems, Erasmus Management Report Series, (263), 1996, 1-37.

9. N.N.: The Death of Distance. In: The Economist, September, 30, 1995, 4-40.

10. N.N.: Del. 3.1 Requirements of VS Design, Report No. 3.2, TELEflow-Consortium, St. Gallen, 1997.

11. N.N.: Del. 11.2 TELEflow Reference Architecture, Report No. 3.2, TELEflow-Consortium, St. Gallen, 1998.

12. Piore, M. J., Sabel, C. F.: The Second Industrial Divide - Possibilities for Prosperity. USA, Basic Books, 1984.

13. Porter, M. E.: How Competitive Forces Shape Strategy, HBR, 57 (2),1979, 137-145.

14. Pumpin, C.: Management Strategischer Erfolgspositionen. Bem, Haupt, 1986.

15. Ritaine, E.: Prato: An Extreme Case of Diffuse Industrialization, International Studies of Management and Organization, 20 (4),1990, 61-76. 